\title{
Frequency of Microsporidial Infection in Immunocompromised Patients with Staining and Molecular Methods Based on Internal Transcribed Spacer Region Gene in Two Cities of Southwest Iran during 2013-2014
}

\author{
Ebrahim Kazemi' ${ }^{1}$, Mehdi Tavalla ${ }^{2 * 3}$, Sharif Maraghi ${ }^{3,4}$, Mohammad \\ Jafaryad Yad ${ }^{5}$ and Mahmoud Latifi \\ 'Department of Medical Parasitology and Mycology, Abadan Arvand International Division, \\ Ahwaz Jundishapur University of Medical Sciences, Ahwaz, Iran \\ ${ }^{2}$ Health Research Institute, Infectious and Tropical Diseases Research Center, \\ Ahwaz Jundishapur University of Medical Sciences, Ahwaz, Iran; dr.mehditavalla@gmail.com \\ ${ }^{3}$ Department of Medical Parasitology, Faculty of Medicine, Ahwaz Jundishapur \\ University of Medical Sciences, Ahwaz, Iran \\ ${ }^{4}$ Health Research Institute, Thalassemia and Hemoglobinopathy Research Center, \\ Ahwaz Jundishapur University of Medical Sciences, Ahwaz, Iran \\ ${ }^{5}$ Abadan Arvand International Division, Ahwaz Jundishapur University of \\ Medical Sciences, Ahwaz, Iran \\ ${ }^{6}$ Department of Epidemiology, Faculty of Health, Ahwaz Jundishapur \\ University of Medical Sciences, Ahwaz, Iran
}

\begin{abstract}
Microsporidiosisis anopportunistic infection frequently diagnosed in immunocompromised patients. Microsporidiosis causes symptomatic or asymptomatic infections immunocompromised/immunosuppressed patients may experience severe and disseminated microsporidiosis. Fecal samples were taken from 186 patients with human immunodeficiency virus (86) and cancer (100). Microsporidia spp. were detected $27.9 \%(24 / 86)$ and $11.6 \%(10 / 86)$ in HIV + patients, $18 \%$ $(18 / 100)$ and $7 \%(7 / 100)$ of cancer patients using polymerase chain reaction (PCR) and trichrome staining respectively. Enterocytozoon bieneusi was detected in 28(66.7\%) patients, while Encephalitozoon intestinalis was detected in 10 (23.8\%) patients. Encephalitozoon cuniculi was detected in only one patient, while Encephalitozoon hellem was detected in three patients. Microsporidia was significantly higher in patients with diarrhea than those without diarrhea $(\mathrm{P}=0.001)$. CD4 T cells blood count was significantly lower $(<200$ cells $/ \mu$ l blood) in HIV+ patients with Microsporidia $(\mathrm{P}=0.001)$. Also, there was significant difference between contact with animals with positive results of HIV+ and cancer patients $(\mathrm{P}<0.005)$. This study confirmed that PCR technique was more sensitive than trichrome staining for diagnosis. Moreover, intestinal microsporidiosis caused diarrhea in HIV+ and cancer patients. This influenced treatment. Therefore, early diagnosis of microsporidiosis is effective on treatment strategies.
\end{abstract}

Keywords: HIV, Immunocompromised Patients, Iran, Microsporidia, PCR

\section{Introduction}

Opportunistic infections are major causes of morbidity and mortality in AIDS and cancer patients receiving chemotherapy. Microsporidia are a group of obligate intracellular parasites which are ubiquitously distributed

*Author for correspondence 
among invertebrate and vertebrate hosts. Nearly 1200 species of Microsporidiah ave been identified of which14 species cause infections in mammals including humans ${ }^{1,2}$. Since the AIDS pandemic around the world in 1980, species of Microsporidia have been recognized as etiologic causes of opportunistic infections. T he clinical symptoms of microsporidiosis depend on the infected site and immune system. Recently, a large number of microsporidiosis cases have been reported as opportunistic infections in patients with $\mathrm{HIV}^{+}$and cancer patient receiving chemotherapy, transplant recipients, passengers, children and the elderly ${ }^{2-7}$. In $\mathrm{HIV}^{+}$patients, Enterocytozoon bieneusi and Encephalitozoon intestinalis are responsible for many gastrointestinal infections in humans ${ }^{8}$. They may cause persistent diarrhea with mal absorption and weight loss, also asymptomatic infections have been reported in immunocompetent persons ${ }^{9}$. Microsporidia may present urinary, pulmonary or disseminate infections includingsinusitis, encephalitis, tracheobronchitis, nephritis, hepatitis, myositis, ocular and stromal keratitis, increasingly are identified by $E$. intestinalis $\mathrm{spp}^{10}$.

Up to 2013 in Iran, $27041 \mathrm{HIV}^{+}$individuals are identified and 1866 out of them are in Khuzestan Province. The number of registered $\mathrm{HIV}^{+}$individuals in Abadan and Khorramshahr cities grew approximately to 460 cases, in which 115 individuals were identified up to 2013 among an estimated population of 342162 citizens (www.IranHIV.com). Based on the 2012 report ofthe National Program of Cancer Register, over 84829 cancer cases have been diagnosed in Iran among 77450000 people; statistics show that 90000 Iranians are expected to have cancer diagnosis ${ }^{11}$.

Human microsporidiosis occurs worldwide, but data on the prevalence and geographic distribution of microsporidial infections are still incomplete and very diverse due to the use of different diagnostic methods, no specialized personal and the focus of parasitic studies on common parasites ${ }^{12}$. Microsporidia have been less reported among cancer patients worldwide ${ }^{13}$; moreover, no studies have been conducted on the prevalence of Microsporidia in cancer patients in Iran despite its occurrence in $\mathrm{HIV}^{+}$population. It has been reported that immunosuppressive therapy may be associated with higher risk of severe parasitic infections ${ }^{13,14}$. To date, many papers reported microsporidial infection in $\mathrm{HIV}^{+}$ patients ${ }^{9}$, but we did not have any precise information of intestinal microsporidiosis infection in this patient in Iran except rare studies that were carried out by Agholiet al., Mirjalali and Ghorbanzadeh ${ }^{15-18}$. Serological assays are not useful for diagnosis, however, they may be used for epidemiological studies. Routine diagnosis is based on spore observation by light microscopy using modified trichrome staining, Uvitex 2B or Fungi flour, but unable to differentiate between the species. However, for the differentiation of the microsporidian species, PCR methods due to their sensitivity and specificity are recommended for this aim ${ }^{19-21}$.To our knowledge, there is no epidemiological study conducted on Microsporidiain Ahvaz area to date. This study determines the frequency of Microsporidia species in fecal isolates of patients with $\mathrm{HIV}^{+}$and cancer receiving chemotherapy in the southwest of Iran (Khuzestan) by using PCR method in comparison with modified trichrome blue (MTB) staining.

\section{Materials and Methods}

\subsection{Sample}

During a period of one year from March 2013 to April 2014, 186 stool samples were collected from patients that were divided into 2 groups on the basis of their cause of illness: Group 1 consisted of $86 \mathrm{HIV}^{+}$patients from 2 hygienic centers (Prevention and Control of Diseases Center) of Khorramshahr and Abadan. Patients included men and women in the age range of 9 to 64 years, who referred to laboratory due to periodic checkup or receiving HAART drug with or without diarrhea. Most of these patients had received antiretroviral therapy (ART); $\mathrm{HIV}^{+} /$AIDS stage of the patients was classified according to CD4+ T-cells levels that fell below 200 cell/ $\mu \mathrm{l}$ is submitted in AIDS stage. Group 2 consisted of 100 cancer patients undergoing chemotherapy. All specimens were randomly obtained from confirmed cancer patients undergoing chemotherapy and/or radiotherapy at different treatment stages with or without diarrhea such as gastrointestinal cancer (31 patient), blood cancer (25 patient), lung cancer (10 patient), liver cancer (7 patient), lymphoma (7 patient), breast cancer (5 patient), prostate cancer (5 patient), skin cancer (4 patient), cervical cancer ( 3 patient) and fallopian cancer ( 3 patient). There were 68 males and 32 females, as all cancer patients referred to the two hospitals in Ahvaz province, Golestan (General Hospital) and Shafa (Thalassemia and Hemoglobinopathy Research Center) of Ahwaz Jundishapur University of Medical Sciences. From each patient one stool sample 
was collected, filtered and stored in $2.5 \% \mathrm{~K}_{2} \mathrm{CrO}_{7}$ at $4{ }^{\circ} \mathrm{C}$ or frozen at $-20{ }^{\circ} \mathrm{C}$ for the tests ${ }^{8}$. Based on the appearance of stool, each sample was considered in one of the grades: formed stool, soft stool or diarrhea stool. CD4+ T cells were counted in blood taken from $86 \mathrm{HIV}^{+}$patients by flow cytometer technique.

\subsection{Questionnaire}

A questionnaire form was designed to collect data related to the presence of microsporidia in during the process of specimen collection for those items (age, sex, HIV/AIDS stage, patient type, location life in a city or rural, contact with animals, CD4 count, with or without diarrhea and drug usage).

\subsection{Staining of Stool Smears}

A stool specimen was mixed with phosphate buffered saline (1:3); the mixture was filtered through a gauze plug and centrifuged at $2000 \mathrm{rpm}$ for $2 \mathrm{~min}$. A thin smear was taken from $20 \mu \mathrm{l}$ pellet suspension of stool and applied on a glass slide; the smear was dried in air and fixed in methanol. Then, it was stained with Modified Weber's Chromo tube based trichrome staining ${ }^{22}$. Smears were tested by oil immersion (1000×magnification) to determine negative specimens. Screening was carried out twice. Pinkish-red oval shape measuring $<2 \mu \mathrm{m}$ in length, with a characteristic posterior vacuole and belt like strike in the middle, were identified as microsporidian spores ${ }^{23}$.

\subsection{DNA Extraction}

DNA extraction and purification were carried out by using QIA amp DNA Stool Mini Kit(QIAGEN) based on instructions from the manufacturer. The stool sample was filtered thrice by a $20 \mu \mathrm{m}$ filter $(25 \mathrm{~mm}$ in diameters) to remove debris. Stool sediment $(100 \mu \mathrm{l})$ was vortexed and suspended in $96 \mu \mathrm{l}$ lysis buffer containing $100 \mathrm{mM}$ ethylene diamine tetra acetic acid $(\mathrm{pH}=8), 100 \mathrm{mM}$ Tris HCL ( $\mathrm{pH}=8$ ), $2 \%$ sodium dodecyl sulfate, $150 \mathrm{mM} \mathrm{NaCl}$ and $0.4 \mathrm{mg} / \mathrm{ml}$ proteinase $\mathrm{K}$ enzyme $(20 \mathrm{mg} / \mathrm{ml})$. The DNA pellet was centrifuged to ensure sedimentation, then obtained DNA was stored at $-20^{\circ} \mathrm{C}^{24}$.

\subsection{PCR Amplification}

Multiplex nested PCR targeted internal transcribed spacer (ITS), small subunits (SSU) and large subunits (LSU) of ribosomal DNA (rDNA). Three sets of primers were used for PCR amplification. Upstream primers MSP-1 (TGA ATG[G/T]GT CCC TGT) and MSP-3 (GGA ATT CAC ACC GCC CGT C[A/G][C/T]TAT) targeted three SSUs and recognized many microsporidian species, such as E. Bieneusi and Encephalitozoon spp. Downstream primers MSP-2B (GTT CAT TCG CAC TAC) and MSP-4B (CCA AGC TTA TGC TTA AGT CCA GGG AGT) targeted five LSUs of E. bieneusi, while MSP-2A (TCA CTC GCC GCT ACT) and MSP-4A (CCA AGC TTA AGT [C/T][A/C]AA[A/G]G GGT) recognized Encephalitozoon $\operatorname{spp}^{8,20,22}$. Finally, reactions occurred in $20 \mu$ containing $0.3 \mathrm{mMdNTPs}, 2 \mathrm{mM} \mathrm{MgCl}$, $1 \mathrm{x}$ PCR buffer, $1 \mathrm{U}$ Taq polymerase (Fermentas), $1 \mu \mathrm{m}$ primer and 3 or 5 of extracted DNA. The first PCR mix contained 1 $\mu \mathrm{l}$ primer (MSP-1, MSP-2A, MSP-2B) and $3 \mu \mathrm{l}$ template $\mathrm{DNA}$. The second nested $\mathrm{PCR}$ reaction involveda mixture containing $1 \mu \mathrm{l}$ primer (MSP-3, MSP-4A, MSP-4B) and $2 \mu \mathrm{l}$ first amplification product mixture. Amplicon size ofMSP-3, MSP-4B product was estimated at500bp for E. bieneusi, while amplicon size of MSP-3, MSP-4A product was estimated at $300 \mathrm{bp}$ for Encephalitozoon spp. Amplifications were doneby using the Applied Biosystems $^{\text {Tw }}$ thermal cyclersfor primary and secondary reactions; these amplifications included denaturation $\left(95^{\circ} \mathrm{C} ; 5 \mathrm{~min}\right), 36$ denaturation cycles $\left(95^{\circ} \mathrm{C} ; 30 \mathrm{~s}\right)$, primer annealing $\left(55^{\circ} \mathrm{C} ; 1 \mathrm{~min}\right)$ and elongation $\left(72^{\circ} \mathrm{C} ; 2 \mathrm{~min}\right)$. The last elongation was extended to $10 \mathrm{~min}$. Each reaction set involved a negative control with ultrapure water and a positive control with the cultured template DNA which was originally isolated from $\mathrm{HIV}^{+}$patients. The amplified products were visualized on $1.5 \%$ agarose gel at $80 \mathrm{KV}$ for $70 \mathrm{~min}$. The gel was stained with $2 \mu \mathrm{g} / \mathrm{ml}$ ethidium bromide and observed under ultraviolet light (Figure 1).

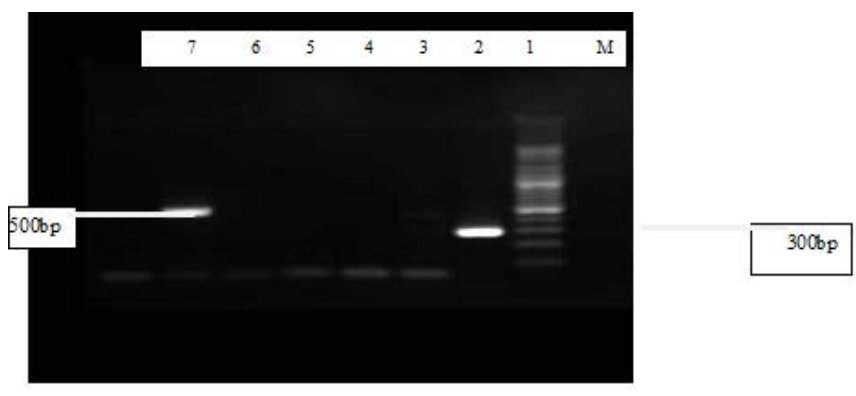

Figure 1. Electrophoresis of Nested PCR product; M: Marker 100bp; 1: Positive sample for Encephalytozoon; 2-34-5: Negative samples; 6: Positive sample for Enterocytozoon; 7: Negative control. 


\subsection{Statistical Analysis}

The student t-test, Chi-square and independent t-test were used to compare means of the studied groups; Fisher's exact test was used to determine factors of microsporidiosis in SPSS 16 software.

\subsection{Ethical Considerations}

This study was approved by the ethics committee (No: ajums.rec.1392.219) of Postgraduate Institute of Medical Education and Research, Jundishapur University of Medical Sciences, Iran.

\subsection{Restriction Fragment Length Polymorphism (RFLP)}

Based on Katzwinkel-Wladarschet al., the RFLP used involved $30 \mu \mathrm{l}$ consisting of $20 \mu \mathrm{l}$ secondary PCR product, $1 \mu \mathrm{l}$ Mnl1 (http://www.thermoscientificbio. com/restriction-enzymes/mnli)enzyme (Fermentas), $0.1 \mu \mathrm{l} \mathrm{BSA}(10 \mathrm{mg} / \mathrm{ml}), 3 \mu \mathrm{l}$ buffer $(10$ concentrated, supplemented with BSA (Fermentas) and $5.9 \mu \mathrm{l}$ super distilled water22. Subsequent incubation $\left(37^{\circ} \mathrm{C}, 12 \mathrm{~h}\right)$ was followed by visualization of fragments in $2 \%$ agarose gel containing $0.2 \mu \mathrm{g} / \mathrm{ml}$ ethidium bromide. The restriction enzyme (Mnl1) cleaved SSU-rDNA sequence into several fragments with species E.bieneusi (500bp) 180, 90, 60bp, E. intestinalis (294bp) 160, $60 \mathrm{bp}$ and three bands under 20bp, E. cuniculi (307bp) 210 and $90 \mathrm{bp}$ and E. hellem (315bp) was expected to produce fragments 180 and 80 bp (Figure 2).

\section{Results}

\subsection{Prevalence of Microsporidia in HIV/ AIDs Patients}

From 86 HIV-infected patients, 24 (27.9\%) patients were positive for microsporidia by PCR and 10 (11.6\%) only by modified trichrome blue staining (Table 1 ). 30 (34.9\%) were female, while 56 (65.1\%) were male, although there was a preponderance of males, there was no significant difference in infection between genders (male vs female $=25 \%$ vs $33.3 \%)(\mathrm{P}=0.412)$. Out of the 24/86 positive specimens, $54.3 \%(19 / 35)$ had diarrhea vs $9.8 \%(5 / 51)$ without diarrhea $(\mathrm{P}=0.001)$ (Table 3$)$. Concurrent infection with E.intestinalis and E.bieneusi was observed in one case. Microsporidia were common in patients aged 28-48 years. The frequency of microsporidia was higher in AIDS stage (51.4\%) than HIV stage (15.8\%).No significant difference $(\mathrm{P}=0.246)$ was found in microsporidia between patients who received treatment (34.2\%) and those who did not receive treatment (22.9\%). There was no significant difference in age, gender, drug use, occupation, and residency of $\mathrm{HIV}^{+}$patients with and without microsporidia. There were significance differences in patients type, life level, living location, contact with animals and with or without diarrhea between positive and negative result of $\mathrm{HIV}^{+}$patients $(\mathrm{P}=0.001)$. Out of 24 positive patients $10(33.3 \%)$ were female and $14(25 \%)$ were male, aged 9-64 years (mean 38.2). Table 2 shows the mean of $\mathrm{CD} 4+$ count of $\mathrm{HIV}^{+}$patients with positive results $(181 \mathrm{cell} / \mu \mathrm{l})$ and $\mathrm{HIV}^{+}$patients with negative result $(483$ cell $/ \mu \mathrm{l})$. Lower CD4+ counts $(<200 \mu \mathrm{l})$ were found in $\mathrm{HIV}^{+}$patients with diarrhea (54.3\%) and patients without diarrhea (9.8\%). There was a statistically significant difference between $\mathrm{CD} 4+$ cell count and $\mathrm{HIV}^{+}$ patients $(\mathrm{P}=0.001)$. By sequencing the amplicons, among the 24 positive patients $17(70.8 \%)$ were identified with $E$. bieneusi and 5 (20.8\%), 1 (4.2\%),1(4.2\%) were identified with E. intestinalis, E. cuniculi and E. hellem, respectively. Also, 1 patient (4.2\%) was diagnosed with concurrent infection of E.bieneusi and E. intestinalis (Table 4).

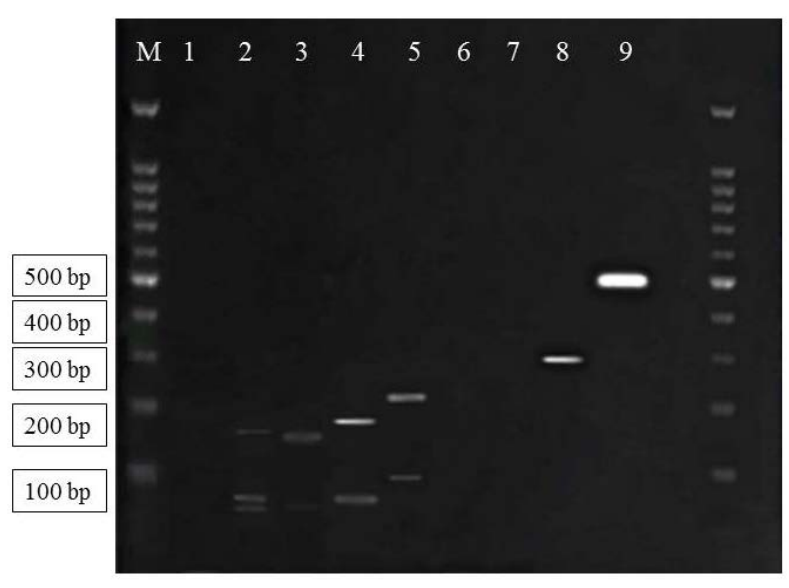

Figure 2. Electrophoresis of RLFP products by MnlI enzyme; M: Molecular Marker 100bp (Fermentas company);1) Negative control; 2) Enterocytozoonbineusi $(60,90,180 \mathrm{bp}) ; 3)$ Encephalitozoonintestinalis (60, 160 bp); 4) Encephalitozoonhellem(80, 180 bp) ; 5) Encephalitozooncaniculi (90, 210 bp); 6,7) Negatives samples; 8)Encephalitozoon control without enzyme;9) Enterocytozoonbineusi control without enzyme. 
Table 1. Prevalence of microsporidia detected by PCR and staining methods in HIV+ patients

\begin{tabular}{lccccc}
\hline Patient & \multicolumn{2}{c}{ PCR } & \multicolumn{2}{c}{ Staining } & Total \\
\cline { 2 - 5 } & Negative & Positive & Negative & Positive & \\
\hline HIV & 48 & 9 & 54 & $3(5.3 \%)$ & 57 \\
& $(84.2 \%)$ & $(15.8 \%)$ & $(94.7 \%)$ & & $(100 \%)$ \\
AIDS & 14 & 15 & 22 & 7 & 29 \\
& $(48.3 \%)$ & $(51.7 \%)$ & $(75.9 \%)$ & $(24.1 \%)$ & $(100 \%)$ \\
\hline Total & $\mathbf{6 2}$ & $\mathbf{2 4}$ & $\mathbf{7 6}$ & $\mathbf{1 0}$ & $\mathbf{8 6}$ \\
& $(\mathbf{7 2 . 1 \% )}$ & $(\mathbf{2 7 . 9 \% )}$ & $(\mathbf{8 8 . 4 \% )}$ & $(\mathbf{1 1 . 6 \% )}$ & $(\mathbf{1 0 0 \% )}$ \\
\hline
\end{tabular}

Table 2. Mean rate of CD4 cells in HIV+ patient with positive and negative results

\begin{tabular}{lcccc}
\hline Cell & PCR & N & Mean & SD $^{*}$ \\
\hline CD4 & Negative & 62 & 483.3065 & 231.70166 \\
& Positive & 24 & 181.8750 & 107.11810 \\
\hline
\end{tabular}

${ }^{*} \mathrm{SD}=$ Standard Deviation

\subsection{Prevalence of Microsporidial Infections in Cancer Patients}

From 100 patient samples, 18/100 (18\%) and 7/100 (7\%) patients were positive for microsporidia by PCR and trichrome staining, respectively (Table 3 ). All smears positive by light microscopy were positive by PCR too. Co-infection was not seen in this group. Microsporidial infection was reported more in gastrointestinal patients (32.3\%), followed by patients with lymphoma (28.6\%), lungcancer (10\%) and blood cancer (8\%)(Table 4). No significance difference was observed in gender, drug usage, patient type, occupation and life level ofcancer patients with positive microsporidian results and cancer patients with negative results; however, number of male patients was higher (68\%). But there were significance differences in age, living location, contact with animals and with or without diarrhea between positive and negative result of cancer patients $(\mathrm{P}=0.011)$ (Table 3). By sequencing of the amplicons, from 18 positive patients, $11(61.1 \%), 5(27.8 \%)$, and $2(11.1 \%)$ were identified with E. bieneusi, E. intestinalis and E. hellem, respectively. No case of E. cuniculi was identified (Table 4).

\subsection{DNA Sequencing}

ABI3730XL sequence analyzer was used for direct sequencing of PCR products. Samples were sequenced in both directions to confirm the species identification. Sequences were aligned and compared with sequences in GenBank. The most prevalent microsporidian species, E.bieneusi, was detected in $17 \mathrm{HIV}^{+}$patients and 11 cancer patients who exhibited $100 \%$ homology with E.bieneusiin GenBank, also amplicons sequencing from 10 patients $\left(5 \mathrm{HIV}^{+}\right.$and 5 cancer patients) were detected with E.intestinalis, exhibited $100 \%$ homology with E.intestinalis in GenBank. E. cuniculiwere identified in one patient; these isolates exhibited $97 \%$ homology with the E. cuniculi sequence reported in GenBank. E. hellem was identified in 3 patients; these isolates exhibited $97 \%$ homology with the E. hellem sequence reported under GenBank.

\section{Discussion and Conclusion}

Prior to the advent of highly active antiretroviral therapy (HAART) in mid-1990, there was 5-50\% reported cases of microsporidiosis in HIV patients worldwide (mean 15\%) and even higher depending on methods of diagnosis, geographical area, hygienic and immune condition of study population ${ }^{25,26}$. By spread of HAART in the developed countries, prevalence of the opportunistic infections including microsporidiosis dramatically declined due to improvements inimmune system $^{2,5,27}$, while opportunistic infections such as microsporidia remain problematic in developing countries where HAART is not easily available for $\mathrm{HIV}^{+}$ patients ${ }^{28,29}$. In Ahvaz, detection of microsporidia is not routinely carried out in hospital or medical diagnostic centers; therefore, little is known about intestinal microsporidiosis in $\mathrm{HIV}^{+}$and cancer patients. This can be attributed to the lack of accurate diagnostic methods, lack of experienced personnel and their very small size for diagnosis. This study was the first epidemiological study in Ahvaz on frequency of microsporidia in 2 groups

Table 3. Prevalence of microsporidia in HIV+ and cancer patients with or without diarrhea by PCR

\begin{tabular}{lcccccc}
\hline \multirow{2}{*}{$\begin{array}{l}\text { Specimen } \\
\text { type }\end{array}$} & \multicolumn{2}{c}{ PCR(HIV $\mathrm{HI}^{+}$patient) } & Total & \multicolumn{2}{c}{ PCR(cancer patient) } & Total \\
\hline Diarrhea & $16(45.7 \%)$ & $19(54.3 \%)$ & $35(100 \%)$ & $18(60 \%)$ & $12(40 \%)$ & $30(100 \%)$ \\
No diarrhea & $46(90.2 \%)$ & $5(9.8 \%)$ & $51(100 \%)$ & $64(91.4 \%)$ & $6(8.6 \%)$ & $70(100 \%)$ \\
\hline Total & $\mathbf{6 2 ( 7 2 . 1 \% )}$ & $\mathbf{2 4 ( 2 7 . 9 \% )}$ & $\mathbf{8 6 ( 1 0 0 \% )}$ & $\mathbf{8 2 ( 8 2 \% )}$ & $\mathbf{1 8 ( 1 8 \% )}$ & $\mathbf{1 0 0}$ \\
\hline
\end{tabular}


Table 4. Frequency of microsporidia species detected among HIV+ and cancer patients by sequencing

\begin{tabular}{|c|c|c|c|c|c|c|c|}
\hline \multirow[t]{3}{*}{ Patients } & \multicolumn{6}{|c|}{ Sequencing } & \multirow[t]{3}{*}{ Total } \\
\hline & \multicolumn{3}{|c|}{ Enterocytozoonbieneusi } & \multicolumn{3}{|c|}{ Encephalitozoon } & \\
\hline & $\mathrm{D}$ & $\mathrm{J}$ & M & intestinalis & cuniculi & hellem & \\
\hline HIV & $5(55.6 \%)$ & 0 & 0 & $2(22.2 \%)$ & $1(11.1 \%)$ & $1(11.1 \%)$ & 9 \\
\hline HIV & $11(73.3 \%)$ & $1(6.7 \%)$ & 0 & $3(20 \%)$ & 0 & 0 & 15 \\
\hline Lym. C & 0 & 0 & 0 & $2(100 \%)$ & 0 & 0 & 2 \\
\hline Gastr. C & $6(60 \%)$ & $1(10 \%)$ & $1(10 \%)$ & $1(10 \%)$ & 0 & $1(10 \%)$ & 10 \\
\hline Blood. C & $1(50 \%)$ & 0 & 0 & $1(50 \%)$ & 0 & 0 & 2 \\
\hline Lung. C & 0 & 0 & $1(100 \%)$ & 0 & 0 & 0 & 1 \\
\hline Liver. C & 0 & 0 & 0 & $1(100 \%)$ & 0 & 0 & 1 \\
\hline Prostate. C & $1(100 \%)$ & 0 & 0 & 0 & 0 & 0 & 1 \\
\hline Skin.C & 0 & 0 & 0 & 0 & 0 & $1(100 \%)$ & 1 \\
\hline Total & $24(57.1 \%)$ & $2(4.8 \%)$ & $2(4.8 \%)$ & $10(23.8 \%)$ & $1(2.4 \%)$ & $3(7.1 \%)$ & 42 \\
\hline
\end{tabular}

of patients at risk for microsporidiosis; $\mathrm{HIV}^{+}$and cancer patients by applying PCR and staining methods. In this study, microsporidiawas more frequent in $\mathrm{HIV}^{+}$group compared to patients receiving chemotherapy $(27.9 \%$ and $18 \%$, respectively).

Prevalence rates of microsporidiosis in $\mathrm{HIV}^{+}$ individuals in this study are similar with previous reports such as in Iran $22.53 \%{ }^{18}$, in Nigeria $23.3 \%^{30}, 27.5 \%$ in $\mathrm{Brazil}^{31}, 26.7 \%$ in India ${ }^{32}$, while higher in reports from Russia $18.9 \%^{8}, 17.4 \%$ Venezuela $^{33}$, 9.5\% Hanoi, Vietnam $^{27}, 10.5 \%$ Tunisia $^{34}, 18.9 \%^{4}$, in India $15.9 \%{ }^{35}, 5.2 \%$ in Cameroon ${ }^{36}, 10.5 \%$ in Niamey, Niger ${ }^{27}$, in India $6.5 \%{ }^{37}$, in Malaysia $8.5 \%{ }^{38}$, in France $10.5 \%^{34}$, whereas lower in $77 \%$ among HIV-infected children in Uganda ${ }^{39}, 42.7 \%$ in Portuga ${ }^{40}, 81.2 \%$ in Thailand ${ }^{41}$. These results are very similar to the prevalence found in patients with HIV in Ethiopia with $39(16 \%)$ by PCR and $18(7.6 \%)$ by staining that Enterocytozoon bieneusi were $77 \%$ (30/39) and Encephalitozoon intestinalis $15.4 \%(6 / 39)^{29}$.In developing countries, prevalence of E.bieneusiis $2.5 \%-51 \%{ }^{9}$ in $\mathrm{HIV}^{+}$ patients with diarrhea and $<5 \%$ in patients without diarrhea $^{36}$. In this study E.bieneusi prevalence rates for $\mathrm{HIV}^{+}$patients with diarrhea was $66.7 \%(16 / 24)$ and $29.2 \%$ (7/24) for patients without diarrhea, therefore the higher occurrence of E.bieneusi is not surprising. In this study, E.bieneusi was identified more than E.intestinalis and also this study identified E.cuniculi and E.hellem and our results supported by the previous study ${ }^{8}$.

In Iran out of $81 \mathrm{HIV}^{+}$patients, $30.86 \%$ were infected with microsporidia and E.bieneusi were identified in all of positive sample and no species of Encephalitozoon were found ${ }^{15}$. E.bieneusi was the most prevalent microsporidian identified in $\mathrm{HIV}^{+}$patients with diarrhea ${ }^{2}$. E.bieneusi and E. intestinalis generally detected in feces and $E$. intestinalis are often disseminated and cause systemic infection ${ }^{42}$. Two other species of Encephalitozoon, E.cuniculi and E.hellem, which are rarely detected in feces usually cause systemic diseases; these species are primarily shed in urine rather than feces $^{2}$. E.cuniculi and E.hellem detected in feces of two patients determine the effect of all three Encephalitozoon species on diarrhea in immunosuppressive and $\mathrm{HIV}^{+}$ patients and this is in agreement with Sokolova finding 8 Diarrhea is common among non- $\mathrm{HIV}^{+}$and immune suppressed patientsin cluding transplant recipients, children and patients with chronic diseases, although the etiology of diarrhea is different in these patients: viral, bacterial, parasitic, oropportunistic intestinal parasites ${ }^{9,43}$. Few cases of microsporidia have been reported in cancer patients with pulmonary infection; this can be attributed to immune suppression caused by treatment in patients with leukemia ${ }^{44}$. In the current study, the majority of infections were caused by E.bieneusi leading to gastrointestinal disorders (32.3\%). This can be attributed tothe depression of cellular immunity which protects the body against microsporidial infections ${ }^{44}$.

In this study, the mean age of cancer patients was 56 years old. It was found that age is a risk factor for infection. 
This is consistent with Loresetal. ${ }^{45}$ Microsporidia was significantly higher in patients with diarrhea (40\%) than patients without diarrhea (8.6\%); however, these values are lower than those reported in previous studies from Malaysia (30\% and $22 \%$ by PCR and MTB, respectively, instool samples of cancer patients) and more common in patients with diarrhea (78\%) than patients without diarrhea $(29.3 \%)^{46,47}$. This finding is also consistent with a study conducted in Egypt where microsporidia were detected in $17 \%$ and $10 \%$ by PCR and MTB, respectively, and infection rate was significantly higher in cancer patients with diarrhea than those without diarrhea. Other studies reported lower rate of microsporidial infection $(8.6 \%$ by MTB and $10.9 \%$ by PCR) in cancer patients ${ }^{14,34}$. Coyle et al. found a clear relationship between microsporidia and diarrhea; they concluded that microsporidia infected $44 \%$ of $\mathrm{HIV}^{+}$patients with diarrhea, whereas it only infected $2.3 \%$ of the patients without diarrhea ${ }^{26}$.

Few studies have been conducted on the prevalence of intestinal microsporidiosis in HIV-immuno suppressed patients, such as cancer patients or transplant recipients ${ }^{6,47}$. In this study, PCR could detect a higher number of positive cases than microscopic-based methods; this is consistent with the previous studies ${ }^{3,22,46}$. Moreover, light microscope does not work when the stool contains undetectable levels of spores; this is consistent with Gumbo et al. ${ }^{48} \mathrm{In}$ Zimbabwe, microsporidia was detected in $18 \%, 51 \%$ of diarrhea patients by microscopic and PCR, respectively. These findings were supported by others who reported PCR is more sensitive(100\%) compared to microscopic techniques in detecting microsporidial infection in $\mathrm{HIV}^{+}$patients ${ }^{34,49,50}$. The increased sensitivity of PCR can be attributed to lower threshold of microsporidia $\left(10^{2}\right.$ spores/g stool) compared to optical microscopy in which the cut-off point ranges from $10^{4}$ to $10^{6}$ spores $^{51}$. Althoughtrichrome staining is are liable and an available technique for detection of microsporidian spores in vitro, detection process is difficult and time-consuming for staining ${ }^{46,52}$.Moreover, higher prevalence of $E$. bieneusi compared to E. intestinalis has been reported in some studies ${ }^{29,36,53}$. While in one study in Egypt in cancer patients reported that $E$. intestinalis was the only species identified and the most prevalent in leukemic patients ${ }^{46}$.As shown in other studies, PCR could detect E. intestinalis (20\%) and E. hellem (10\%) in stool samples taken from cancer patients ${ }^{20}$, while Chabchoub et al found equal prevalence of E. intestinalis and E. hellem
$(33.3 \%)^{34}$. Similarly, higher prevalence of E. intestinalis has been reported among HIV patients ${ }^{9,38,46}$. In our study prevalence rate of microsporidia in cancer patients is $18 \%$ and this result is similar with $21.9 \%$ in Malaysia, $17 \%$ in Poland in transplant recipients, $20.77 \%$ in Mexico in all patients $\mathrm{s}^{3,54,55}$ and higher than previous report with $4.8 \%$ in cancer patients in Egypt, 15.1\% in cancer patients in Iraq, and $10 \%$ in Turkey ${ }^{14,56}$.

Animal contact cancontribute to the transmission of microsporidia to $\mathrm{HIV}^{+}$and cancer patients. Birds are natural hosts of $E$. hellem ${ }^{57,58}$. Conversely, humans infected with E. intestinalis transmit this species ${ }^{12}$. Moreover, E.bieneusi infects a wider range of both animals and humans; the genotype identified in currentsamples is $\mathrm{M}, \mathrm{J}, \mathrm{D}$. This finding is in agreement with previous report ${ }^{8}$. This intestinal parasite istransmitted by contaminated food or water. Therefore, it is more difficult to reduce the risk of transmission of intestinal microsporidial infection in developing countries ${ }^{59}$. Thus, $\mathrm{HIV}^{+}$and cancer patients need proper personal hygiene; for example, they need to boil the water before drinking. Those $\mathrm{HIV}^{+}$ patients with $<100$ cells $/ \mathrm{mm}^{3} \mathrm{CD} 4+$ cell counts are highly susceptible to intestinal microsporidiosis ${ }^{29}$. In this study,CD4+ cell count was $<200$ cells $/ \mathrm{mm}^{3}$ in more than half of $\mathrm{HIV}^{+}$patients with intestinal microsporidiosis. Findings of this study are consistent with previous reports on the relationship between microsporidiosis in patients with lower CD4+ T cells ${ }^{4,46}$. Further studies are required o determine the sources of these infections to reduce their prevalence and determine microsporidian infections, which cause disseminated diseases in $\mathrm{HIV}^{+}$ and immune suppressed patients. Inconsistency of the results can be attributed to manners of stool preparation or DNA extraction. DNA extraction from microsporidia spores in stool has many complexities including very small size of spores, rigid doubled-layer wall and also lower counts of stool samples. Moreover, immune suppression, geographical and socioeconomic factors source of infection, and diagnostic tests used can impress the quality and quantity of molecular results ${ }^{19,21,46}$.In conclusion, the occurrence of microsporidia in patients with $\mathrm{HIV}^{+}$and cancer patients at the level of $27.9 \%$ and $18 \%$ respectively, suggests that these pathogens should be taken into account when other etiological agents cannot be found in those diarrheic patients. Moreover, this study shows that PCR is able to detect and identify species of intestinal microsporidia with the highest sensitivity 
than traditionally used staining methods. Therefore, these patients might maintain good personal hygiene for prevention and applying proper treatment.

\section{Acknowledgments}

We gratefully acknowledge from the Department of Parasitology, Jundishapur university of Medical Sciences. We also thank two hygienic centers personals (Disease control and prevention of Abadan and Khorramshahr) for the assistance in collecting samples from HIV-infected individual. We also appreciate the personal of Golestan and Shafa Hospital for the assistance in collecting samples from cancer patients. This study is a summary of a $\mathrm{PhD}$ thesis supervised by Jundishapur University of Medical Sciences, Iran (Grant No: 91-01-160-B-9220).

\section{References}

1. Didier ES, Didier PJ, Snowden KF, Shadduck JA. Microsporidiosis in mammals. Microbes and Infection. 2000;2(6):709-20.

2. Didier ES, Weiss LM. Microsporidiosis: current status. Current opinion in infectious diseases. 2006;19(5):485.

3. 3.Eligio-García L, Cano-Estrada A, Cortés-Campos A, Medina-Sansón A, Jiménez-Cardoso E. Identification of Microsporidium spp. in patients with acute lymphoblastic leukemia. Boletín Médico del Hospital Infantil de México. 2013;70(1):26-30.

4. Dascomb K, Frazer T, Clark RA, Kissinger P, Didier E. Microsporidiosis and HIV. JAIDS Journal of Acquired Immune Deficiency Syndromes. 2000;24(3):290-2.

5. Dworkin MS, Buskin SE, Davidson AJ, Cohn DL, Morse A, Inungu J, et al. Prevalence of intestinal microsporidiosis in human immunodeficiency virus-infected patients with diarrhea in major United States cities. Revista do Instituto de Medicina Tropical de São Paulo. 2007;49(6):339-42.

6. Galván A, Sánchez AM, Valentín MP, Henriques-Gil N, Izquierdo F, Fenoy S, et al. First cases of microsporidiosis in transplant recipients in Spain and review of the literature. Journal of Clinical Microbiology. 2011;49(4):1301-6.

7. Wichro E, Hoelzl D, Krause R, Bertha G, Reinthaler F, Wenisch C. Microsporidiosis in travel-associated chronic diarrhea in immune-competent patients. The American Journal of Tropical Medicine and Hygiene. 2005;73(2):285-7.

8. Sokolova OI, Demyanov AV, Bowers LC, Didier ES, Yakovlev AV, Skarlato SO, et al. Emerging microsporidian infections in Russian HIV-infected patients. Journal of Clinical Microbiology. 2011;49(6):2102-8.

9. 9.Sak B, Brady D, Pelikánová $M$, Květoňová D, Rost $M$, Kostka $\mathrm{M}$, et al. Unapparent microsporidial infection among immunocompetent humans in the Czech Republic. Journal of Clinical Microbiology. 2011;49(3):1064-70.

10. Franzen C. Microsporidia: a review of 150 years of research. Open Parasitol J. 2008;2:1-34.

11. WHO. Cancer control programe.NCD country profiles. 2011.

12. Didier ES. Microsporidiosis: an emerging and opportunistic infection in humans and animals. Acta Tropica. 2005;94(1):61-76.

13. Botero JH, Castaño A, Montoya MN, Ocampo NE, Hurtado MI, Lopera MM. A preliminary study of the prevalence of intestinal parasites in immunocompromised patients with and without gastrointestinal manifestations. Revista do Instituto de Medicina Tropical de São Paulo. 2003;45(4):197-200.

14. Karaman U, Atambay M, Daldal N, Colak C. The prevalence of Microsporidium among patients given a diagnosis of cancer. Turkiye parazitolDerg. 2008;32(2):109-12.

15. Mirjalali H, Mohebali M, Mirhendi H, Gholami R, Keshavarz $\mathrm{H}$, Meamar AR, et al. Emerging intestinal microsporidia infection in HIV+/AIDS patients in Iran: microscopic and molecular detection. Iranian Journal of Parasitology. 2014;9(2):149-54.

16. Agholi M, Hatam GR, Motazedian MH. HIV/AIDS-associated opportunistic protozoal diarrhea. AIDS Research and Human Retroviruses. 2013;29(1):35-41.

17. Agholi M, Hatam GR, Motazedian MH. Microsporidia and coccidia as causes of persistence diarrhea among liver transplant children: incidence rate and species/genotypes. The Pediatric Infectious Disease Journal. 2013;32(2):185-7.

18. 18.Ghorbanzadeh B, Sadraie J, Emadi Kuchak H. Diagnosis of Cryptosporidium and intestinal Microsporidia in HIV/ AIDS patients with staining and PCR methods on 16srRNA gen. Arak Medical University Journal. 2012;15(7):37-47.

19. Franzen C, Müller A. Molecular techniques for detection, species differentiation, and phylogenetic analysis of microsporidia. Clinical Microbiology Reviews. 1999;12(2):243-85.

20. Ghosh K, Weiss LM. Molecular diagnostic tests for microsporidia. Interdisciplinary Perspectives on Infectious Diseases. 2009; 2009(1);1-13.

21. Subrungruang I, Mungthin M, Chavalitshewinkoon-Petmitr P, Rangsin R, Naaglor T, Leelayoova S. Evaluation of DNA extraction and PCR methods for detection of Enterocytozoon bienuesi in stool specimens. Journal of Clinical Microbiology. 2004;42(8):3490-4.

22. Katzwinkel-Wladarsch S, Lieb M, Heise W, Löscher T, Rinder H. Direct amplification and species determination of microsporidian DNA from stool specimens. Tropical Medicine and International Health. 1996;1(3):373-8.

23. Bendall R, Chiodini P. New diagnostic methods for parasitic infections. Current Opinion in Infectious Diseases. 1993;6(3):318-22.

24. Velásquez JN, Carnevale S, Guarnera EA, Labbé JH, Chertcoff A, Cabrera MG, et al. Detection of the microsporidian 
parasite Enterocytozoon bieneusi in specimens from patients with AIDS by PCR. Journal of Clinical Microbiology. 1996;34(12):3230-2.

25. Bryan R, Schwartz D. Epidemiology of microsporidiosis. The Microsporidia and Microsporidiosis. 1999; 1(1):50216.

26. Coyle CM, Wittner M, Kotler DP, Noyer C, Orenstein JM, Tanowitz HB, et al. Prevalence of microsporidiosis due to Enterocytozoon bieneusi and Encephalitozoon (Septata) intestinalis among patients with AIDS-related diarrhea: determination by polymerase chain reaction to the microsporidian small-subunit rRNA gene. Clinical Infectious Diseases. 1996;23(5):1002-6.

27. Espern A, Morio F, Miegeville M, Illa H, Abdoulaye M, Meyssonnier V, et al. Molecular study of microsporidiosis due to Enterocytozoon bieneusi and Encephalitozoon intestinalis among human immunodeficiency virus-infected patients from two geographical areas: Niamey, Niger, and Hanoi, Vietnam. Journal of Clinical Microbiology. 2007;45(9):2999-3002.

28. Breton J, Bart-Delabesse E, Biligui S, Carbone A, Seiller X, Okome-Nkoumou $\mathrm{M}$, et al. New highly divergent rRNA sequence among biodiverse genotypes of Enterocytozoon bieneusi strains isolated from humans in Gabon and Cameroon. Journal of Clinical Microbiology. 2007;45(8):2580-9.

29. Endeshaw T, Kebede A, Verweij JJ, Zewide A, Tsige K, Abraham Y, et al. Intestinal microsporidiosis in diarrheal patients infected with human immunodeficiency virus-1 in Addis Ababa, Ethiopia. Japanese Journal of Infectious Diseases. 2006;59(5):306.

30. Ojuromi OT, Izquierdo F, Fenoy S, Fagbenro-Beyioku A, Oyibo W, Akanmu A. Identification and characterization of microsporidia from fecal samples of HIV-positive patients from Lagos, Nigeria. PloS One. 2012;7(4): e35239.

31. Brasil P, de Lima DB, de Paiva DD, de Castro Lobo MS, Sodré FC, da Silva SP, et al. Clinical and diagnostic aspects of intestinal microsporidiosis in HIV-infected patients with chronic diarrhea in Rio de Janeiro, Brazil. Revista do Instituto de Medicina Tropical de Sao Paulo. 2000;42(6):299304.

32. Kulkarni S, Kairon R, Sane S, Padmawar P, Kale V, Thakar $\mathrm{M}$, et al. Opportunistic parasitic infections in HIV/AIDS patients presenting with diarrhoea by the level of immunesuppression. 2009.

33. Chacin-Bonilla L, Panunzio AP, Monsalve-Castillo FM, Parra-Cepeda IE, Martinez R. Microsporidiosis in Venezuela: Prevalence of intestinal microsporidiosis and its contribution to diarrhea in a group of Human Immunodeficiency Virus-infected patients from Zulia State. The American Journal of Tropical Medicine and Hygiene. 2006;74(3):4826.

34. Chabchoub N, Abdelmalek R, Mellouli F, Kanoun F, Thellier M, Bouratbine A, et al. Genetic identification of intestinal microsporidia species in immunocompromised patients in Tunisia. The American Journal of Tropical Medicine and Hygiene. 2009;80(1):24-7.

35. Saigal K, Sharma A, Sehgal R, Sharma P, Malla N, Khura- na S. Intestinal microsporidiosis in India: A two year study. Parasitology International. 2013;62(1):53-6.

36. Sarfati C, Bourgeois A, Menotti J, Liégeois F, Moyou-Somo R, Delaporte E, et al. Prevalence of intestinal parasites including microsporidia in human immunodeficiency virus-infected adults in Cameroon: a cross-sectional study. The American Journal of Tropical Medicine and Hygiene. 2006;74(1):162-4.

37. Kumar SS, Ananthan S, Joyee A. Detection of Enterocytozoon bieneusi (Microsporidia) by polymerase chain reaction (PCR) using species-specific primer in stool samples of HIV patients. Indian J Med Res. 2005;121(4):215-9.

38. Lono A, Kumar S, Chye TT. Detection of microsporidia in local HIV-positive population in Malaysia. Transactions of the Royal Society of Tropical Medicine and Hygiene. 2011;105(7):409-13.

39. Tumwine JK, Kekitiinwa A, Bakeera-Kitaka S, Ndeezi G, Downing R, Feng X, et al. Cryptosporidiosis and microsporidiosis in Ugandan children with persistent diarrhea with and without concurrent infection with the human immunodeficiency virus. The American Journal of Tropical Medicine and Hygiene. 2005;73(5):921-5.

40. Ferreira FM, Bezerra L, Santos MBG, Bernardes RM, Avelino I, Silva MS. Intestinal microsporidiosis: a current infection in HIV-seropositive patients in Portugal. Microbes and Infection. 2001;3(12):1015-9.

41. Viriyavejakul P, Nintasen R, Punsawad C, Chaisri U, Punpoowong B, Riganti M. High prevalence of Microsporidium infection in HIV-infected patients.Southeast Asian J Trop Med Public Health. 2009 Mar; 40(2):223-8.

42. Kotler DP, Orenstein JM. Clinical syndromes associated with microsporidiosis. Advances in Parasitology. 1998;40:321-49.

43. Germani Y, Minssart P, Vohito M, Yassibanda S, Glaziou $\mathrm{P}$, Hocquet D, et al. Etiologies of acute, persistent, and dysenteric diarrheas in adults in Bangui, Central African Republic, in relation to human immunodeficiency virus serostatus. The American Journal of Tropical Medicine and Hygiene. 1998;59(6):1008-14.

44. Eser B, 체lent. A case of pulmonary Microsporidiasis in an acute myeloblastic leukemia (AML)-M3 patient. Yonsei Medical Journal. 2003;44(1):146-9.

45. Beatriz L, Isabel L-M, Cristina A, Soledad F, Julio T, del Aguila C. Intestinal microsporidiosis due to Enterocytozoon bieneusi in elderly human immunodeficiency virusnegative patients from Vigo, Spain. Clinical Infectious Diseases. 2002;34(7):918-21.

46. El Sobky M, El Nahas N. Detection and differentiation between Enterocytozoon bieneusi and Encephalitozoon intestinalis species in cancer patient's stools using PCR compared with different staining methods. PUJ; 2012.

47. Lono AR, Kumar S, Chye TT. Incidence of microsporidia in cancer patients. Journal of Gastrointestinal Cancer. 2008;39(1-4):124-9.

48. Gumbo T, Hobbs RE, Carlyn C, Hall G, Isada CM. Microsporidia infection in transplant patients. Transplantation. 1999;67(3):482-4. 
49. Verweij JJ, ten Hove R, Brienen EA, van Lieshout L. Multiplex detection ofEnterocytozoon bieneusi andEncephalitozoon spp. in fecal samples using real-time PCR. Diagnostic Microbiology and Infectious Disease. 2007;57(2):163-7.

50. Anane S, Attouchi H. Microsporidiosis: epidemiology, clinical data and therapy. Gastroenterologie Clinique et $\mathrm{Bi}$ ologique. 2010;34(8):450-64.

51. 51.Thellier M, Breton J. Enterocytozoon bieneusi in human and animals, focus on laboratory identification and molecular epidemiology. Parasite. 2008;15(3):349-58.

52. Patil K, De A, Mathur M. Comparison of weber green and ryan blue modified trichrome staining for the diagnosis of microsporidial spores from stool samples of HIV-positive patients with diarrhoea. Indian Journal of Medical Microbiology. 2008;26(4):407-.

53. Polley SD, Boadi S, Watson J, Curry A, Chiodini PL. Detection and species identification of microsporidial infections using SYBR Green real-time PCR. Journal of Medical Microbiology. 2011;60(4):459-66.

54. Angela R, Suresh K. Microsporidia in stool from cancer patients. J Med Sci. 2007;1(2):88-90.

55. Bednarska M, Bajer A, Siński E, Wolska-Kuśnierz B, Samoliński B, Graczyk T. Occurrence of intestinal mi- crosporidia in immunodeficient patients in Poland. Annals of Agricultural and Environmental Medicine: AAEM. 2014;21(2):244-8.

56. El-Mahallawy H, Zaki MM, El-Arousy M, Shalabi L, Mansour T. Diagnosis of intestinal microsporidiosis in pediatric oncology patients in Egypt using modified acid fast trichrome staining versus PCR. Acta Parasitologica. 2011;56(4):348-52.

57. Kašičková D, Sak B, Kváč M, Ditrich O. Sources of potentially infectious human microsporidia: molecular characterisation of microsporidia isolates from exotic birds in the Czech Republic, prevalence study and importance of birds in epidemiology of the human microsporidial infections. Veterinary Parasitology. 2009;165(1):125-30.

58. Snowden K, Logan K, Phalen D. Isolation and characterization of an avian isolate of Encephalitozoon hellem. Parasitology. 2000;121(1):9-14.

59. Weber R, Bryan RT, Schwartz DA, Owen RL. Human microsporidial infections. Clinical Microbiology Reviews. 1994;7(4):426. 